\title{
Foraging for Transdisciplinary Challenges: Emergent Industrial Themes
}

\author{
Emily CAREY ${ }^{1}$, Linda NEWNES, Susan LATTANZIO, Alex HULTIN and Nataliya \\ MOGLES, \\ University of Bath, $U K$
}

\begin{abstract}
This paper presents our findings from thirteen industrial interviews, to investigate the significance of transdisciplinarity (TD) in an industrial context. Thus to gain insight into the resilience of industrial manufacturing in rapidly changing environments and establish what enabling or disabling practices may currently exist. The interviews were conducted as an initial part of a wider case study approach being undertaken by the TREND research team and were semi-structured in format. We present the background and research questions being addressed and outline our exploratory research approach. The analysis of interview transcriptions is provided answering our research questions and identifying any emerging themes. Of the industry interviews, only five interviewees had heard of the term TD, the definition of TD varied between companies and did not align with the primordial system of Jantsch's work. A number of focal enabling and disabling industrial themes emerge from the interviews and related discourse such as the positive and negative human contribution(s) and growing global teams involved in manufacture. For industry to be resilient and meet rapid technological and societal change, these themes should be core for manufacturing solutions. Secondary studies should investigate literature and collaborate with engineering industries to test any potential TD interventions.
\end{abstract}

Keywords. Transdisciplinary, Industry Context, Semi-Structured Interviews, Industrial Resilience

\section{Introduction}

Engineering industries are facing increasing pressure from the need to solve complex societal and global problems, facing rapid change in technological means and societal needs [1][2]. Currency for remaining competitive in recent years has changed from innovative product provision to the addition of services [3]. The requirements to be met by engineers in a modern society is indeed changing again as consumers look to sustainable solutions, to mitigate demanding issues such as climate change or vaccine development [4]. Remaining resilient in the face of dramatic change and disruption in industrial manufacture, is urgently becoming a priority for industries to remain viable [1][5], hence adaptability and strategies in the face of change is the focus of this paper.

One such approach to support industrial resilience that has gained more attention is the development of "transdisciplinarity" (TD) and applying associated methods as a solution [6][7]. This is clearly evident in the increased number of peer reviewed TD literature and in the focus of funding calls of research councils [2]. While TD aims to expand disciplines to address complexity it also contributes to the need to be ahead of

\footnotetext{
${ }^{1}$ Corresponding Author, Mail: emcc20@bath.ac.uk.
} 
change, in engaging early with policy and society [8]. The intent being that industry will be aware and develop early capacity, hence being adaptable and more resilient in the face of continuing disruption [1]. Given the notion of TD being a useful solution, research has not yet focussed on the extent of TD projects and its current impact in industry [6] but on specific industrial needs such as collaboration [9]. This paper seeks to close the TD gap and focus on the current needs and understanding of industrial partners, in respect of their position and engagement with the TD agenda.

Without prior established engagment of practitioners in industry to evaluate their TD position and with the knowledge debate in academic circles about the core components of TD projects [10], the language and definitions being utilised cannot be assumed. Hence an exploratory approach using a case study method begins building a robust picture of the current state of TD in industry [11], this was also used in new areas such a collaborative engineering [9]. This paper reports findings from 13 industrial engineering interviews to contribute to understanding concerns in industry in respect of using TD approaches, with a particular focus upon currently enabling or disabling practices. This is a first step to close the gap in industry need for meeting TD projects, facilitating the uptake of industry practice adaptions to meet increasing societal change.

In the sections that follow first we describe the research approach and design of semi-structured interviews. This is split into the overarching case study approach taken by the TREND team [13] with specific research questions, then a semi-structured interview approach is outlined. A description of the data transcription and analysis is then provided and followed by results that describe the industry sampling and summarise themes emerging from the data. Our discussion highlights what the authors perceive are the significant findings and suggest future TD industry collaboration to address complex competing demands and for the resilience of global engineering in the future [1][6].

\section{Background Literature}

Much work in manufacturing and in engineering design research has sought to develop support interventions to overcome the need for engineers to be adaptable and hence resilient to the operational changes bought about by revolutions such as Industry 4.0 [1]. Work conducted by Carey et al. [14] investigated the reasons for limited uptake of such support interventions. The work suggests that there are eight key issues that pose problems limiting the usefulness of support in practice. These factors likewise will pose limits for wider engineering projects in implementing solutions to remain adaptable and resilient in current manufacturing climes, especially with current focus being societal need [2][4]. Changing requirements and pressures being placed upon engineers are similar to those of design engineering in-service provision changes, where remaining resilient and rapidly adapting skills [15] with limited costs, resources and increasing competition pose overbearing challenge [3][1].

Recent emphasis in projects and engineering is being placed on higher disciplinary approaches such as TD to develop sustainable engineering solutions providing societal value [13]. It is application of TD practices that the explorations of this work investigate, or the readiness and utilisation of such already in industry, if it is indeed present [6]. It is notable in literature that a multiplicity of definitions and language exist for TD projects [2][10]. This poses significant challenges in investigating such issues within industry, both for purporting concepts to those less familiar outside of academia and in interpreting the language being used informally to portray similar concepts. To overcome this it has 
been necessary to utilise a primordial definition of TD such as the first systematic approaches defined by Jantch [16], to enable clear expression and a framework for presenting TD concepts. In more recent work significant language being used in TD academic literature has been distilled into the top most frequent concepts that should comprise TD projects [10]. This model supports to provide a collective TD representation for comparing the industrial findings and concepts that emerge from this study.

\section{Exploratory Research Approach: Case and Interview Design}

To date much of literature about TD has placed emphasis on academic research, with one of the definitive TD threads referrring to industry and stakeholders [13]. Engineering research in the UK is embedded in industrial settings [4] and efforts outlined in this paper seek to provide initial insights into the impact of TD in industry and to establish collaboration in TD projects. In the context of research-industry collaboration, interviews are a research method used to build explorative case studies [11][12], with the express goal of identifying industrial contexts, needs and existing practices of engineering organisations dealing with complex problems [4]. The semi-structured interview approach is used to build industrial case studies incrementally, exploring first the uptake of TD and industrial readiness for adaptation and competitiveness in societally focussed projects. This was an express first attempt to communicate complex academic TD conceptualisations to industry, uniting academic and non-academic language, goals and mind-sets [6]. The main research questions investigated in the forage interviews are shown in Figure 1 below.

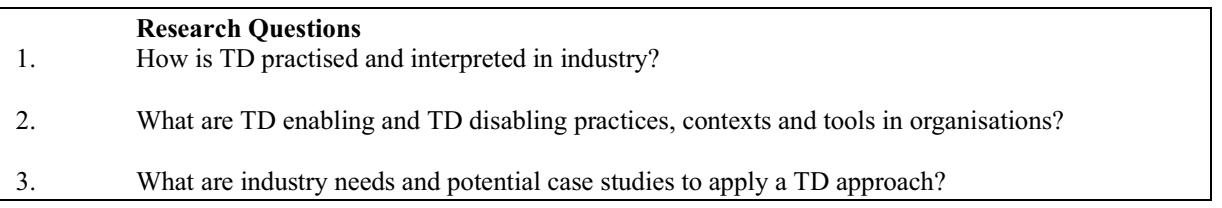

Figure 1. Research Questions

Participants invited were in managerial positions, having both authority to engage with our research and having project know how to answer our questions. Engineering companies were contacted by email and asked to participate in our interviews. A pilot interview was conducted with an internal colleague with significant industrial experience, to test question objectives and wording. This led to a two interviewer approach being recorded by dictaphone and informed consent forms signed prior. Copy interview transcripts were sent with a thank you email two weeks after each interview.

\subsection{Data Collection Semi-Structured Interviews}

Scripted semi-structured interviews and questions [17][18] designed to gather industry expert opinions on the TD topic are shown in Table 1. A semi-structured approach enabled a broad case of each industry to be captured in directly comparable answers. The open ended nature of questions encouraged discourse, seeking depth to find the perspectives of each interviewee, and a rich exploration of the companies involved [18]. 
The questions were designed to collate background data about the nature of each industry's engineering focus, together with experience levels of each of the interviewees for contrasting in our analysis. In this way both the personal TD mindset could be established as well as understanding the functional industrial readiness.

In the pilot interview it was necessary to present a clear foundational academic TD [17][18] to frame the questions being asked overcoming multiplicity in language and concepts [10]. To avoid personal influence creating bias [17][18], we used scripted TD questions, a short video describing all "disciplinarities" based on Jantsch's definitions not our own [16], an interview protocol and documented information briefings [19].

Table 1. Interview Script

\begin{tabular}{|c|c|}
\hline & Interview Question Wording \\
\hline Background & $\begin{array}{ll}\text { 1. } & \text { Organisation name } \\
\text { 2. } & \text { Main sector } \\
\text { 3. Nature of services or products: B2B, B2C, B2G, mixed } \\
\text { 4. Number of employees } \\
\text { 5. Role within an Organisation } \\
\text { 6. Years of experience: in general/in the current Organisation } \\
\text { 7. Age range: } 18-30,31-40,41-50,51-65,65+ \\
\text { 8. Gender } \\
\text { 9. } \\
\text { Organisational structure: Traditional Hierarchy, Flatter, Flat, Flatarchies, } \\
\text { Holacratic }\end{array}$ \\
\hline Main Script & $\begin{array}{l}\text { 10. We are conducting research on a TD approach in engineering. Have you ever } \\
\text { heard of this term? } \\
\text { 11. YES: What is it? (Would you consider having social scientists, political } \\
\text { 12. This is what we mean (pyramid of Jantsch's definition of TD explain). What } \\
\text { ways do you work in your organisation? Why? } \\
\text { 13. YES: Could you provide examples? } \\
\text { 14. YES: What tools helped you to work in a TD manner? } \\
\text { 15. NO: Are you aware of applications of TD approaches in other organisations? } \\
\text { 16. NO: Can you think of where it can be useful? Possible problems and contexts? } \\
\text { 17. NO: What tools can help to achieve TD? } \\
\text { 18. Could you anticipate barriers for the implementation of this approach? } \\
\text { 19. How to mitigate these challenges? } \\
\text { 20. How do you think it's possible to measure/evaluate a TD approach success? } \\
\text { 21. Do you have a project that has a TD opportunity? We would like to work } \\
\text { together on it to improve its efficiency? What's the possibility? }\end{array}$ \\
\hline Closing & $\begin{array}{l}\text { 22. Feedback on the interview: were the questions appropriate? Were the questions } \\
\text { understandable? Was the terminology and wording clear? } \\
\text { 23. Is interview a good method to gather the information on TD practices or would } \\
\text { surveys or focus groups be more convenient or appropriate? } \\
\text { 24. What can we offer to industry to get them on-board? } \\
\text { 25. What are your expectations regarding the current collaboration: timeline, } \\
\text { outputs, intellectual property (IP)? }\end{array}$ \\
\hline
\end{tabular}

\subsection{Transcription and Identifying Common Themes}

Interview audio recordings totalled 650 hours and were transcribed by the TREND group familiar with its content. Each transcript has been annonymised using interview ID's for subsequent coding of responses into summarised common content. The design of the interviews encouraged discussion and debate about the academic disciplinary schools of thought presented. Due to size, the results presented here are limited to quantitative 
summaries and richer qualitative data is not presented. The transcript data was analysed by two researchers, independently coding content and collating responses. The enablers, disablers and associated discourse has been coded to group common themes for comparison.

\section{Results: Sample Descriptives and Emerging Themes}

In total TREND researchers conducted 13 interviews. These were recorded by dictaphone, then transcribed and coded. All interviewees represented an engineering company and held project manager or managerial roles.

\subsection{Sample Descriptives}

A summary of the companies and their backgrounds is provided in Table 2 below.

Table 2. Companies Background

\begin{tabular}{cll}
\hline Company Sector & \multicolumn{1}{c}{ Products/Services } & Number of Employees \\
\hline Healthcare and Disability & B2B, B2C, B2G & 30 \\
Automotive & Design \& Manufacture & 4000 \\
Water & Services & 450 \\
Food Packaging & B2B & 24000 \\
IT & B2B, B2C & 20 \\
Aerospace & Consultancy & 1 \\
Energy & B2B & 3 \\
Engineering Consultancy & B2B & 2 \\
Design & B2C & 7 \\
Automotive & Products \& Services & 44000 \\
Life Sciences & Mixed & 5000 \\
Additive Manufacturing & B2B & 57 \\
Defense and Maritime & B2B & 1500 \\
\hline
\end{tabular}

The companies participating in the interviews were all engineering businesses, but covered a wide range of sectors, from healthcare, food packaging and maritime, meaning a broad industrial perspective is represented. Similarly the business' agenda extended from design and consultancy through to manufacture and provision of services, encompassing views of the entire engineering product, manufacture to service lifecycle. The size and scale of the companies interviewed ranged from small enterprises with 1 employee, through to large scale manufacturing businesses with approximately 44,000 employees world wide. The sample is broad but useful as an exploratory snapshot of industrial perspectives.

\subsection{Question Highlights}

Responses to the questions asked in the interviews have been directly coded per question and collectively reported for the purposes of this paper to represent common themes that emerge from the content. The overarching aim of the interviews and value in the study of the additional discourse has been in identifying common content raised. The highlights of which are summarised in this section.

Only 5 out of 13 companies representated had heard the term TD. Of those 5 there was one company represented that had heard of the term in relation to their current work, and a second in a prior company. One interviewee had heard of the term from their own university studies and 2 used different disciplinary concepts such as cross-discipline 
interchangeably with TD. The other 8 interviewees had not heard of the term prior to discussion with the research team. This was opportunity to present new approaches to industry and to collect their unbiased views on the significance of disciplinarities in the workplace.

The structured TD presentation within the body of the interview, enabled the industrial interviewees to reflect upon projects they have been involved in. Including those, that whilst not named TD within industry, might be deemed to be TD in nature. Each and every interviewee was able to name one or more project that they worked on in their current industry that was in fact TD, suggesting that TD projects are already very much part of current industry portfolios and TD approaches relevant. Table 3 below collates the types of TD projects highlighted and illustrates common TD project topics already in engineering industry.

Table 3. TD Project Examples

\begin{tabular}{cl}
\hline Project Type & Number of Suggestions \\
\hline Health & 3 \\
Sustainability & 7 \\
Environment & 7 \\
Business Planning & 3 \\
Product Development & 3 \\
Systems Engineering & 1 \\
IT & 3 \\
Global Supply Chain & 1 \\
Design & 2 \\
Product Lifecycle & 2 \\
Small Medium Enterprise & 1 \\
\hline
\end{tabular}

Specific project examples named, are diverse in nature but common topics are respresented, examples of such TD projects included "a powered wheelchair(s)", "recycling projects", "reducing emissions in cities" and the "design and implementation of a statue internationally". Generalised examples included "sustainability projects", "business plan preparation" or "systems engineering solutions". Although the number of industries interviewed remains small it is evident that there is overwhelming focus upon "sustainability" and "environmental" TD projects (approximately $42 \%$ of projects discussed). Evidence in examples given suggest that TD projects exist through the entire product and manufacture lifecycle.

\subsection{TD enablers and disablers}

In respect of the TD projects highlighted, interviewees were asked to reflect upon the strengths and weaknesses in their current industrial working practice, in carrying out these projects. These were described as "enablers" or "disablers" in current industrial practice. In analysing these a large list of industrial challenges together with potential solutions was elicited from interview responses. Due to their large number and diverse nature these disablers and enablers have been content coded into common groups for comparison in Figure 2. For the purposes of summarisation representative collective content names have been identified to create themes illustrating the distribution of topics. Common topics emerge such as "communication" or "human" working elements, and each response has been distilled into such categories. It is possible that one response could be categorised into multiple themes, for example "lack of knowledge at the top of command" might fall into "knowledge" and "management" categories. These distilled 
guiding themes within transcripts are coupled with active verbal descriptors such as "understanding" or "transition" and it is expected that further analysis will change the depth of understanding. These verbal descriptors suggest an element of change is still required to achieve any enabling outcomes, or work to make project(s) achieve TD status in practice. Thus it is possible to infer areas both industry and researchers may need to collaborate and focus efforts to develop approaches to support industrial change in practice.

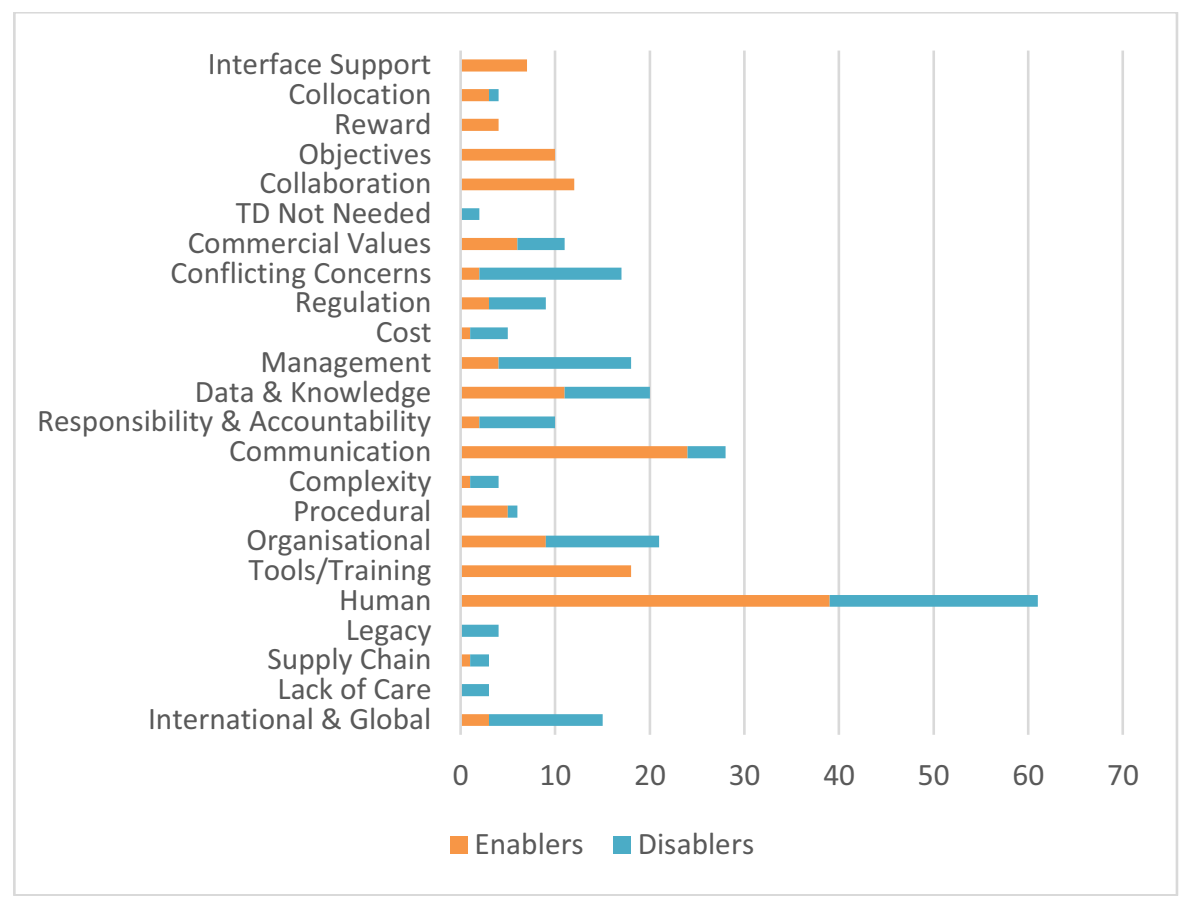

Figure 2. Distribution of Themes

The enablers and disablers presented in figure 2 above illustrate the pervasive presence of TD projects already across the depth and breadth of industrial work, demonstrated in the broad topics. More enablers were suggested than disablers, suggeting a positive approach within indutry to solving such TD problems ( 50 disablers vs 59 enablers). However, in practice this could mean there are multiple solutions for each and every challenge, whilst this is useful, it could in itself pose the problem of optimal solution finding. Figure 2 above stacks the number of responses that pertain to core themes for all of the responses provided. This provides a useful visual snap shot of current core topics emerging in industry, in repect of enabling vs disabling practices and a summary of the overall themes.

A number of suggestions from responses are evident; 1 . The most enabling project features pertain to human working, communication facilitation, collaboration, objective setting, data \& knowledge of projects and the tools \& technologies available. 2. The most limiting or disabling project features are also human working, organisational set up, international \& global projects, management, data \& knowledge, responsibility \& accountability and the presence of conflicting concerns in projects. 3 . The most apparent issues for industry in the low ratio of enabling features vs disabling features could be deemed to be, that TD is not needed, that there are conflicting concerns in projects, 
difficulties with meeting regulations, cost issues, management issues, responsibility \& accountability, organisational conerns and international \& global working issues.

It follows the above points are pressing concerns for industry, but interpretation suggests for each disabling project feature, alternative enablers may in fact contribute to providing support. However, the response illustration allows reflection upon project features appearing most enabling or disabling. Owing to the complex nature of descriptions it is possible that one response could be encoded into multiple categories, for example it may pertain to both "knowledge intergration" and "model", indicating difficulty establishing independent themes. It is not possible here to present interdependencies that may exist but requires further in depth evaluation.

\section{Discussion}

The absence of literature outlining industrial TD engineering studies [6], the complexities of TD definitions from literature [2][10] and the limited uptake of support in industry [14] raise the need for industrial studies such as the interviews in this paper. Hence the findings outlined in this paper provide value in answering the research questions in figure 1 and to begin exploring issues affecting both the resilience of engineering industry [1] and readiness to apply solutions such as TD approaches.

It is a surprise given prior work suggests the TD nature of health [10], that only 3 health projects were found in industry TD project examples. This is in comparison to the 14 for both sustainability and environmental projects. This does not reflect overall funding bodies within UKRI [4] where there appears more equal distribution of topics, however, it may reflect where current engineering industry focus is, or could be popular in societal or government policy [8]. The same studies conducted now during the covid pandemic unsurprisingly would shift significantly towards health, suggesting societal need focuses heavily in industry [15]. This demonstrates the need for resilience within industry to adapt to the rapid changes and effects of government policy and societal need.

It also means that while engineers are typically expected to generate solutions, often project disablers "fall outside of industrial organisations remit" or into catergories outside of a typical engineers skill profile [8][15], such as "management", "organisational" or "international \& global". The effects of government and wider policy change in TD challenges such as "sustainability" also raise industrial cost challenges (figure 2), that create further "conflicting concerns". Enablers suggested could be "embed quality engineers" or "members into customer businesses", or other experts into wider team working. This would however in practice require modified engineering skill sets and be difficult to implement across entire projects, especially where data and information is deemed to be either commerically sensitive, or as in most cases has personal informative elements, such as in health.

Themes in interview data highlight huge differences from prior TD language and concepts used in academia [10]. This means that there are still language barriers in interpreting current industrial terminology and contexts. This significant issue must be addressed if one of the disabling and enabling issues is to be overcome "communication", especially if TD is to become relevant to industrial partners. It is also evident many industry challenges raised are not coupled closely to academic suggestion of TD outcomes when we directly compare frequent concepts [10][6][14]. Societal value is a paramount TD output [2][7][16] but the disablers in industry do not map to this directly. This gap between research and practice is also noted in the work by Scholz et al. [6]. 
Some of the TD approach benefits, such as "effective communication" [16] also feature in the industrial engineering disablers (figure 2), where "global \& interntional" teams implement global sustainable solutions. The disabler "conflicting concerns" in industry is prevalent highlighting that industrial benefits of TD may not overlap with societal benefits, indicating there needs to be a resolution or adaptability somewhere in the wider project parties [6][14]. There is no simple solution to this issue, but it reflects industry concerns in management and communication.

Interdisciplinary (ID)/TD overlaps suggested in the work by Carey et al. [10], such as "climate change" appear in the industry projects and arguably many of the disabling and enabling topics could relate to both ID or TD. Further issues in the uptake of solutions [14] show considerable overlap in industry disablers, such as "data and knowledge". This raises two issues for the future, that industry continues to use different language and academic efforts should seek to understand the overlap. Secondly, it raises the question whether issues already being worked on as ID in industrial practice or indeed in wider intervention fields such as knowledge managament [3][14] also need to be acknowledged as their methods may support TD practice. It was indeed suggested within interviews that "TD is not needed" and being clear about where it may be more beneficial to industry needs clarity. A TE index measure to resolve where there is need for TD is currently being worked upon by the TREND team [13]. It illustrates the limiting human understanding factors in TD, that have sought to be solved in the work by [3][14] and further establishment of core clusters of TD concepts in the artifical clustering work being used by TREND [13]. With future research in mind, methods need to extend the findings of such academic literature content into industry to better understand language and relevant conceptual themes in engineering contexts.

\section{Conclusions}

In this paper we set out an initial industry exploration using semi-structured interviews with the express aim of understanding TD concepts, language and approaches being utilised in engineering projects. This included answering three research questions, to establish is there TD work already in industry without explicit mention of TD, what are the enabling and disabling factors for TD in industry and to initiate deeper case study of TD in practise.

In describing our 13 industrial interviews we found industrial projects that could be defined as TD, but limited industry understanding mean the concept of TD is not widely used. This highlights continued communication and language barriers to overcome in differing industrial disciplinarities and wider engagement. Even though terms being utilised in engineering industries do describe projects bearing similarity to those academics might consider TD, such as sustainability or environment. TD projects exemplified span the product/manufacturing lifecycle, meaning TD need is pervasive and evidence suggest disablers include mitigating for conflicting project concerns, management, international or global working and human obstacles. Enabling features include similar themes such as human solutions, tools and training, communication, collaboration and data and knowledge. Gaps appear in provision where disabling issues reside with little counteracting enabling practise, such as mitigating for conflicting concerns, international and global working and management.

It is these gaps research work for TD industries should be focussed upon supporting, especially if industry is to remain resilient whilst establishing TD projects. With this in 
mind researchers should drive deeper understanding of specific industry need, to establish common language across societal, industrial and policy actors and act as a bridge to implement TD tools, training and technologies. This will better common understanding of the value that is required of engineering solutions, that all stakeholders can buy into and be achievable for industries given the current working climates.

\section{Acknowledgement}

The work reported in this paper was undertaken as part of the Designing the Future: Resilient Trans-Disciplinary Design Engineers Project, at the Universities of Bath, Bristol and Surrey. The project is funded by the Engineering and Physical Sciences Research Council (EPSRC) Grant EP/R013179/1.

\section{References}

[1] C. Goncalves Machado, M. Peter Winroth, E. Hans Dener Ribeiro da Silva, Sustainable Manufacturing in Industry 4.0: An Emerging Research Agenda, International Journal of Production Research, 2020, Vol 58:5, pp. 1462-1484.

[2] S. Lattanzio, E. Carey, A. Hultin, R. Imani Asrai, M. McManus, N. Mogles, G. Parry and L.B. Newnes, Transdisciplinarity Within the Academic Engineering Literature, International Journal of Agile Systems and Management, 2020, Vol. 13(2), pp. 213-232.

[3] E. Carey, S. Culley, \& F. Weber, Establishing Key Elements for Handling In-Service Information and Knowledge, International Conference on Engineering Design, 2013, pp. 11-20.

[4] UKRI. Manufacturing the future. 2021 [cited 202124 February]; Available from: https://epsrc.ukri.org/research/ourportfolio/themes/manufacturingthefuture/.

[5] M. Morisse \& C. Prigge, Design of a Business Resilience Model for Industry 4.0 Manufacturers, TwentyThird Americas Conference on Information Systems, 2017 , https://core.ac.uk/download/pdf/301371962.pdf, Accessed July, 12021.

[6] R.W. Scholz and G. Steiner, Transdisciplinarity at the crossroads. Sustainability Science, 2015, Vol. 10(4), pp. 521-526.

[7] N. Wognum, C. Bil, F. Elgh, M. Peruzzini, J. Stjepandic and W.J.C. Verhagen, Transdisciplinary systems engineering: implications, challenges and research agenda, International Journal of Agile Systems and Management, Vol. 12, 2019, pp. 58-89.

[8] Rhodes, C., Briefing Paper Number 01942. Manufacturing: statistics and policy. 2020, The House of Commons Library research service: UK.

[9] M. Borsato, M. Peruzzini, Collaborative Engineering. In: Stjepandić, J., Wognum, N., et al (Ed.). Concurrent Engineering in the 21st Century. Springer International Publishing, 2015, pp.165-196.

[10] E. Carey, J. Gopsill \& L. Newnes, Text Analysis of Disciplinary Research Papers, Advances in Transdisciplinary Engineering, Vol. 12, 2020, pp. 32-41.

[11] Gillham, B. (2000). Case study research methods. Bloomsbury Publishing.

[12] Yin, R. K. (2011). Applications of case study research. Sage.

[13] The University of Bath. TRansdisciplinary Engineering Design (TREND). 2021 [cited 202124 February]; Available from: https://www.bath.ac.uk/projects/transdisciplinary-engineering-design-trend/.

[14] E. Carey, S. Culley, H. McAlpine, F. Weber \& Y. Xie, Key Issues in the Take-Up of Knowledge Management Interventions in Engineering Design, International Design Conference, 2012.

[15] J. Sajdakova. E. Carey, V. Dhokia \& L. Newnes, Mapping the Competencies of Design Engineers Against the Jantsch's Hierarchical System, Advances in Transdisciplinary Engineering, Vol. 12, 2020, pp. 13-22.

[16] CERI, Interdisciplinarity: Problems of teaching and research in Universities. 1972.

[17] M. C. Harrell \& M. A. Bradley, Data collection methods. Semi-structured interviews and focus groups. Rand National Defense Research Inst santa monica ca, 2009.

[18] S. E. Rabionet, How I Learned to Design and Conduct Semi-Structured Interviews: An Ongoing and Continuous Journey. Qualitative Report, 16(2), 2011, pp. 563-566.

[19] Hierarchy illustration. [online]. Accessed:14122019. Available: https:/online.pointpark.edu/business/types-of-organizational-structures/ 